
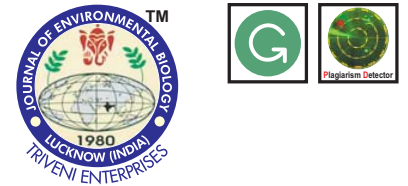

\title{
Allelopathic effects among selected species of phytoplankton and macrophytes
}

\section{Authors Info \\ D. Chicalote-Castillo', P. Ramírez-García ${ }^{1 *}$ and M.L. Macías-Rubalcava ${ }^{2}$ \\ 'Universidad Nacional Autónoma de México, FES-Iztacala, Research and Postgraduate Division, Av. de los Barrios No. 1, 54090 Tlalnepantla, Estado de México, México \\ ${ }^{2}$ Universidad Nacional Autónoma de Mexico. Institute of Chemistry Department of Natural Products Ciudad Universitaria, Mexico City, Del.Coyoacán 04510, Mexico}

${ }^{*}$ Corresponding Author Email : micro@unam.mx

Key words

Allelopathy

Microcystis aeruginosa

Phragmites australis

Scenedesmus acutus

Schoenoplectus californicus

Publication Info

Paper received: 13.09 .2016

Revised received: 03.01.2017

Re-revised received : 24.05 .2017

Accepted : 11.08.2017

\section{Abstract}

Aim: To understand the allelopathy among different taxonomic levels of freshwater photoautotrophs, the effect of aqueous extracts of Phragmites australis and Schoenoplectus californicus on monocultures of Microcystis aeruginosa and Scenedesmus acutus was investigated. In addition, the cell extract and filtered medium of each phytoplankton species were used and tested between them.

Methodology: In the macrophyte bioassays against alga, the allelopathic effect was evaluated separately using 10 and $20 \mathrm{mg}$ of aqueous extract of leaf, stem and rhizome of Phragmites, as well as the stem and rhizome of Schoenoplectus. In the assays between the phytoplankton species, the cell extract $\left(12.44 \pm 0.16 \mathrm{ug}^{-1}\right.$ microcistin-LR equivalents) and the filtered culture medium $\left(2.98 \pm 0.03 \mathrm{\mu gl}^{-1}\right.$ microcistin-LR equivalents) of Microcystis were used in 100 and $50 \%$ and were added to the Scenedesmus monocultures. In the same proportion, the cell extract and the filtered culture medium of Scenedesmus on monocultures of Microcystis were used.

Results: In Phragmites, leaf extract showed greater inhibition activity than the other plant organs on Microcystis cultures. The stem and rhizome showed a larger decrease for the growth of Scenedesmus cultures. For Schoenoplectus, the stem extract showed a greater inhibitory effect than the rhizome extract; this was observed on both alga and cyanobacteria. Microcystis when in contact with the cellular extract of Scenedesmus, it was observed that the bioactive containing substances in the extract had a greater inhibitory activity.

Interpretation: The leaf, stem and rhizome extracts of Phragmites and Schoenoplectus showed a different affinity of the allelopathic activity on Microcystis and Scenedesmus, suggesting a speciesspecific relationship.

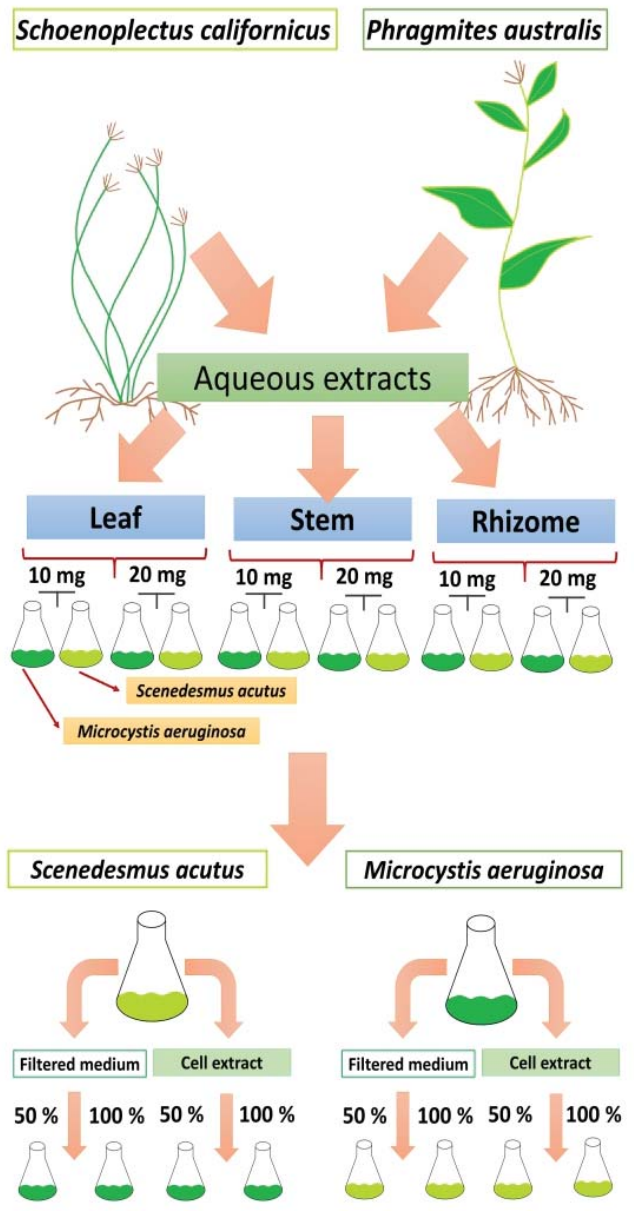




\section{Introduction}

Allelopathy prevents competitors from making use of available resources, affecting growth and distribution of other species and therefore can control the environment in which they live (Thorpe et al., 2011). In aquatic systems, macrophytes released infochemicals through of root, stem or leaf (Gross et al., 2007; Uddin et al., 2012). Species of phytoplankton release their bioactive compounds directly into water or are retained in the sediment (Bhadoria, 2011). The allelopathic effects of substances from macrophytes on the harmful algal blooms are gaining importance recently (Hong-Qiang et al., 2014). However, it is expected that active compounds released from macrophytes reach the recipient species and somehow affect their metabolism (Gao et al., 2011; Gross et al., 2012). From the macrophyte Phragmites, the most frequent allelochemicals are phenols, in particular gallic acid and to a lesser extent the organic acid ethyl 2-methylacetoacetate, which are obtained from exudates and roots. The leaf contains allelochemicals such as taraxerol and taraxeron. The allelopathic effect of these compounds have been evaluated on cultures of Chlorella pyrenoidosa and Microcystis aeruginosa (Li and Hu, 2005; Rudrappa et al., 2007). Phenolic compounds are also produced by Schoenoplectus, which have been isolated from the whole plant. The phenol (-) catechin showed a similar algaecide effect to that of $\mathrm{CuSO}_{4}$ to Selenastrum capricornutum (D'Abrosca et al., 2006). However, its effect on cyanobacteria such as Microcystis aeruginosa has not been tested.

Cyanobacterial blooms generally produce secondary metabolites such as cyanotoxins, which can be released directly into the environment by senescence or cell lysis (Dittmann et al., 2013; Neilan et al., 2013). Cyanotoxins may cause damage directly (lethal) or indirectly (chronic) to different aquatic organisms due to accumulation effect. Their main function is the growth inhibition in other organisms, reducing the number of species that are potential competitors or grazers (Lin et al., 2014; Rao et al., 2015). In Microcystis aeruginosa the mechanism of action of its toxins affects several Chlorophytes such as Chlamydomonas neglecta, C. reinhardtii, Chlorella ellipsoidea, C. pyrenoidosa, C. vulgaris and Monoraphidium convolutum (Ishida and Murakami, 2000; Yang et al., 2014; BittencourtOliveira et al., 2015).

Few studies have assessed the effect of dissolved microcystins and cyanobacterial biomass containing toxins at concentrations similar those found in nature $\left(1-10 \mu \mathrm{g} \mathrm{I}^{-1}\right.$ microcystin-LR) to phytoplankton species (Kearns and Hunter, 2001; Bittencourt-Oliveira et al., 2013). Many photoautotrophs are capable of producing bioactive substances (Erhard, 2006). For example, chemicals released by Scenedesmus are capable of inhibiting the growth of $M$. aeruginosa (Jia et al., 2008; Chen and Guo, 2014). Species interaction experiments usually are done to provoke the release of allelochemicals in the producer species (Bittencourt-Oliveira et al., 2015). However, bioactive substances are permanently present in algae and since they are fundamental part of the physiological processes, they are involved in the growth and development. These in turn may function as interacting substances with the environment in adaptation and defense, as is the case with cyanotoxins (Leflaive and Ten-Hage, 2007). Therefore, it is necessary to know the allelopathic effects of common photoautotrophic organisms in aquatic systems for understanding the role of allelopathic processes in nature.

The aim of the present work was to evaluate the allelopathic effect of aqueous extracts of $P$. australis and $S$. californicus to $M$. aeruginosa and $S$. acutus and to quantify the effect of conditioned medium from $M$. aeruginosa on $S$. acutus and vice versa.

\section{Materials and Methods}

Culture conditions : M. aeruginosa was isolated from Valle de Bravo reservoir, State of Mexico (Mexico) while $S$. acutus (Meyen) (strain no. 72) was obtained from the University of Texas, (Austin, Texas). Both the species were cultured on Z8 liquid medium (Staub, 1961; NIVA, 1972). The cultures were homogenized using an orbital shaker at $90 \mathrm{rpm}$ (Labnet, Orbit 1900 ) at $26 \pm 2^{\circ} \mathrm{C}, \mathrm{pH} 6.8$ and a photosynthetic active radiation (PAR) of $90 \mu \mathrm{mol}$ photons $\mathrm{m}^{-2} \mathrm{~s}^{-1}$, using cold white fluorescent light with a photoperiod of $14: 10 \mathrm{~h}$ (light/dark). PAR was measured through a quantum sensor equipped with a semispherical sensor (Apogee Instruments, MQ-200). The emergent macrophytes, $P$. australis and $S$. californicus were collected from the La mintzita reservoir (State of Michoacán, Mexico). Whole plants were selected. Six plants of Phragmites and Schoenoplectus were taken with an average length of $1.61 \pm 0.04$ and $1.63 \pm 0.09 \mathrm{~m}$, respectively.

Aqueous extracts, cell extracts and filtered culture medium : The macrophytes were dried at $26 \pm 2^{\circ} \mathrm{C}$ for five days. Each of the three structures (leaf, stem and rhizome) plant were weighed (20 $\mathrm{g}$ ), which were separately macerated with $50 \mathrm{ml}$ water chromatographic grade (Sigma-Aldrich 34877) for $24 \mathrm{hr}$. Subsequently the first extracts were filtered by filter paper (Whatman qualitative, Grade 1) and lyophilized (Labcono, LYPH LOCK 4.5). The extract was filtered by Millipore system with 0.45 $\mu \mathrm{m}$ nitrocellulose membrane (Merck, MF-Millipore HAWP04700), that was used in the assays.

Algal aqueous extracts were separately obtained from the cultures in $350 \mathrm{ml}$ of Z8 medium, whose cell density was $2.90 \pm$ $0.46 \times 10^{6}$ cell ml $l^{-1}$ for $M$. aeruginosa and $2.90 \pm 0.46 \times 10^{6} \mathrm{cell} \mathrm{m}^{-1}$ for $S$. acutus. The cells were centrifuged at $10,000 \mathrm{rpm}$ for $5 \mathrm{~min}$ (BOECO, SC-8). The sediment was lyophilized and $0.5 \mathrm{~g}$ dry weight of algal biomass was used and suspended in $150 \mathrm{ml}$ of fresh Z8 medium. The extract was filtered with $0.45 \mu \mathrm{m}$ membrane. The supernatant was filtered through the Millipore 
system with the same membrane pore size for the aqueous extract.

Quantification of microcystin concentration: The microcystins, both dissolved and intracellular form were analyzed with a Quanti Plate ${ }^{\mathrm{TM}}$ Kit for Microcystin (Envirologix). The analyses were done in triplicates and the results were expressed as $\mu \mathrm{gl}^{-1}$ microcistin-LR equivalents.

Allelopathy bioassays: For the macrophyte bioassays against phytoplankton (alga and cyanobacterium), we used 10 and $20 \mathrm{mg}$ of aqueous extract from leaf, stem and rhizome of Phragmites, and the stem and rhizome of Schoenoplectus. For the algal bioassay, the cell extract $\left(12.44 \pm 0.16 \mu \mathrm{g} \mathrm{l}^{-1}\right.$ microcistin-LR equivalents) and the filtered culture medium $\left(2.98 \pm 0.03 \mathrm{Mg} \mathrm{I}^{-1}\right.$ microcistin-LR equivalents) of Microcystis (as 100 and $50 \%$ ) were added to the Scenedesmus cultures. In the same proportion, the cell extract and the filtered medium of Scenedesmus were added to the cultures of Microcystis. Both the phytoplankton species were cultured in triplicate in $25 \mathrm{ml}$ volume of $Z 8$ medium. The cell densities of Scenedesmus and Microcystis were separately estimated using a hemocytometer at initial, day 2 and day 4 after
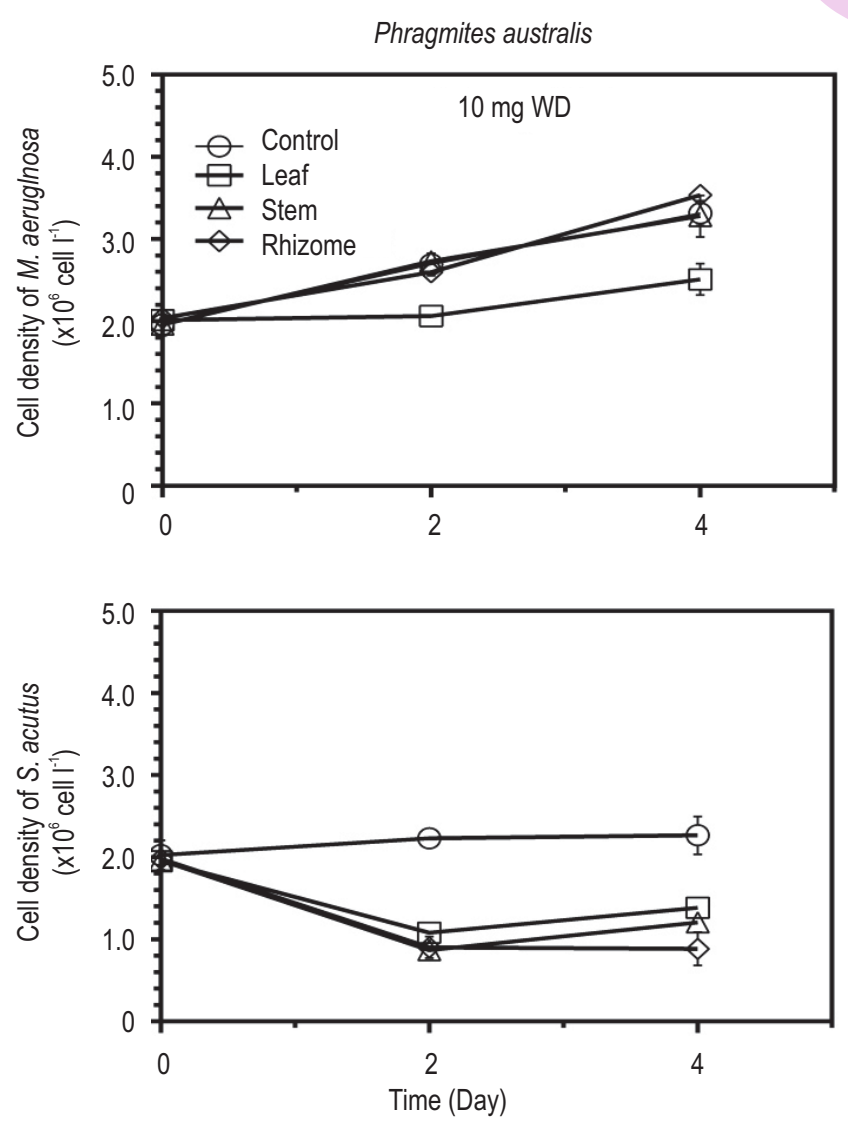

fixing the samples in $20 \%$ Lugol. When cell counting was performed to determine the effect of the extracts and to compare it with the cell number of the control cultures, it was observed that the decrease of the organisms below the cell inoculum at day zero was due to the fragmentation and agglomeration of the cells, so that the cell portions were not considered in the cell count for the results.

Two-way repeated measures ANOVA was applied with a post hoc means analysis using a Bonferroni's multiple comparisons test with an alpha of 0.05 level of significance to compare growth differences among treatments.

\section{Results and Discussion}

The $10 \mathrm{mg}$ aqueous extract of Phragmites on Microcystis cultures showed that the leaf had an inhibiting effect. This decrease was maintained during the 4 days of the trial. A significant difference $(p<0.01)$ was observed in the cell density in cultures with the extract vs Microcystis controls. The stem and rhizome extracts showed no significant effects ( $p>0.05$ ). Scenedesmus was sensitive to the extracts from Phragmites. The
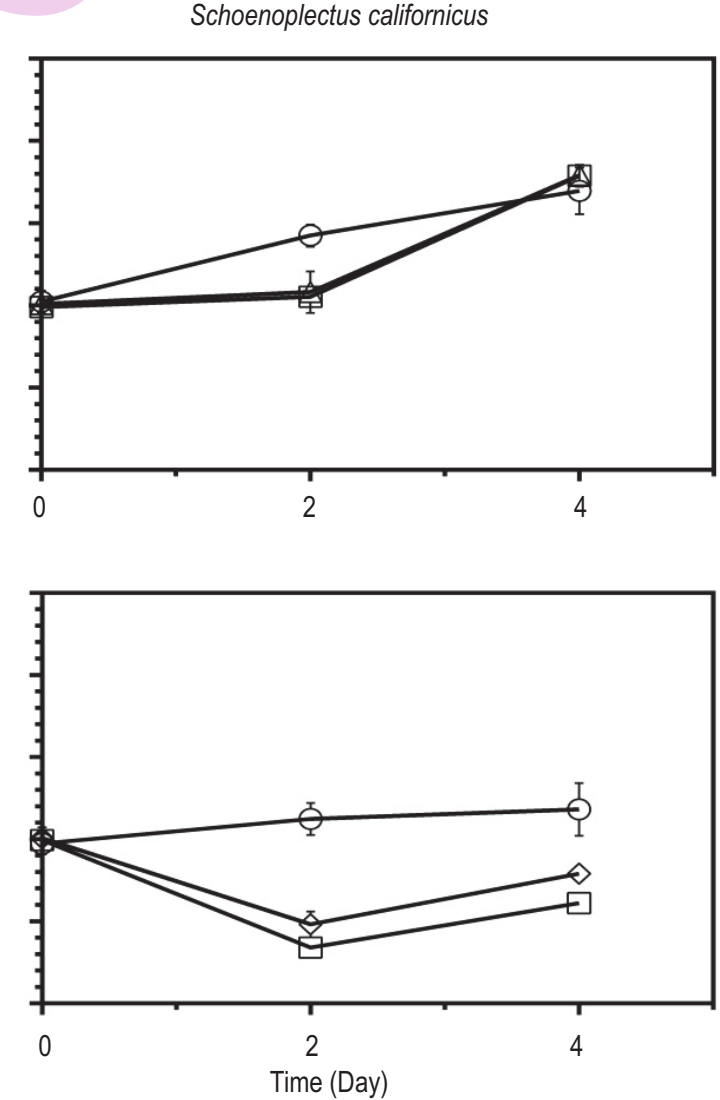

Fig. 1 : The effect of $10 \mathrm{mg}$ concentration in dry weight of the aqueous extracts of each macrophytes structural parts $P$. australis and S. californicus to M. aeruginosa and $S$. acutus are shown. Error bars are based in three replicates 

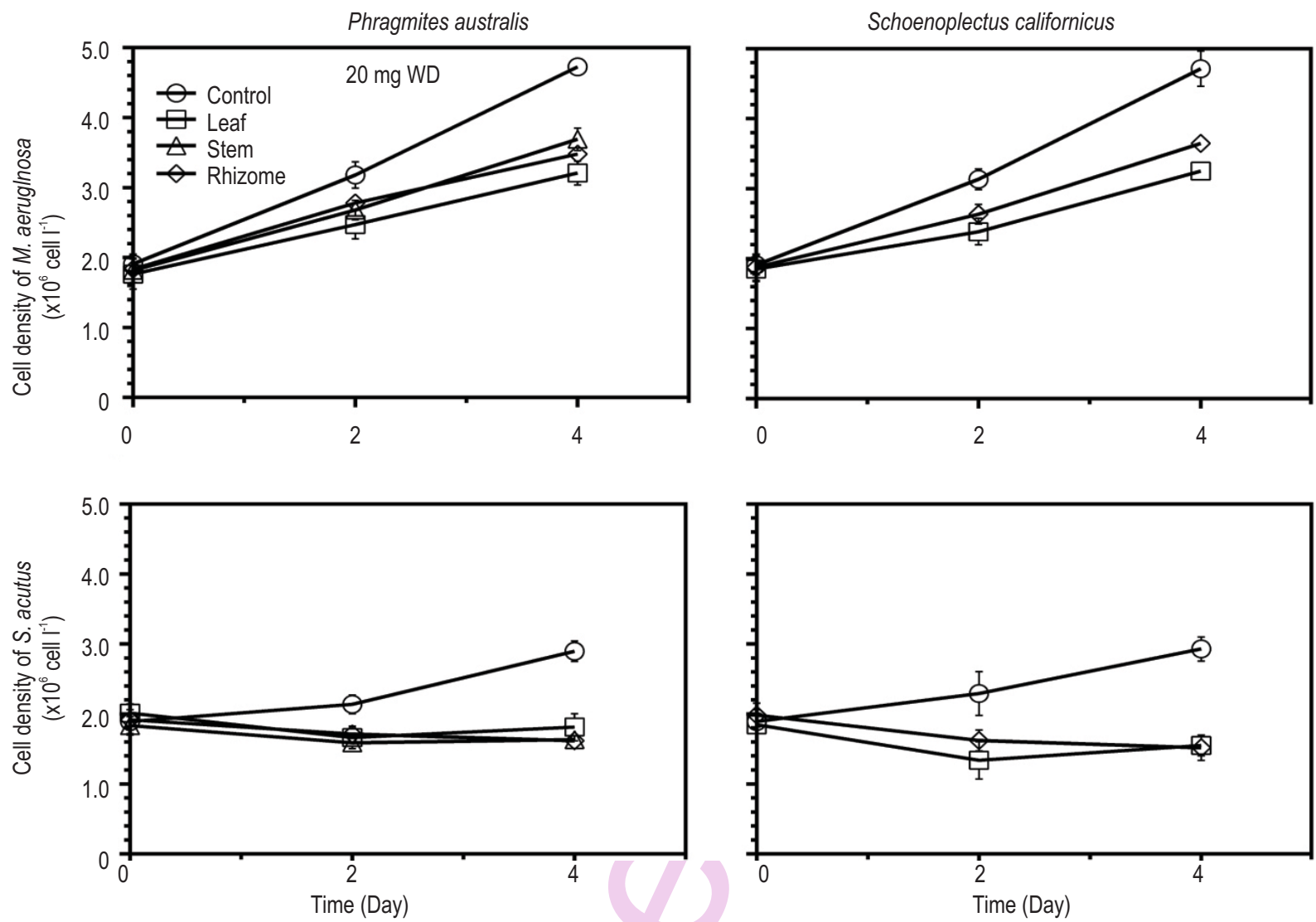

Fig. 2 : A concentration of $20 \mathrm{mg}$ of each extract of $P$. australis and $S$. californicus was used to evaluate the allelopathic effect against the phytoplankton species $M$. aeruginosa and $S$. acutus. Error bars are based in three replicates

significant $(p<0.01)$ inhibitory effects were observed during the four days of the experiment. The stem and rhizome extracts of Schoenoplectus decreased the growth of Microcystis. A significant difference $(p<0.01)$ was observed only on day 2 as compared to control. At day 4, both extracts lost their inhibition effect, so that Microcystis was able to reach densities similar to control. In Scenedesmus it was observed that the low growth was maintained to a greater degree by the stem extract during the experiment. The negative effect of both extracts were significantly different $(p<0.01)$ from controls and by day 4 the effect of the extracts was lower (Fig. 1).

At $20 \mathrm{mg}$ concentration, the leaf extract showed a greater negative effect on the growth of Microcystis, followed by stem and rhizome, the lower effects being on day 2. The three extracts had a negative effect on Microcystis and there were significances among them $(p<0.01)$ to the cell growth in the control cultures. The growth of Scenedesmus differed significantly $(p<0.01)$ from controls with the three extracts of $20 \mathrm{mg}$ of Phragmites. The extracts of Schoenoplectus also showed a tendency of inhibition on both Microcystis and Scenedesmus. However, it was observed that Microcystis is able to increase its cell number despite exposure to extracts unlike Scenedesmus where the inhibition effect was maintained during the assay (Fig. 2).

The recurrent tendency of decreasing effects of the extracts from both macrophytes is due to bioactive substances, mainly phenols. These compounds are prone to oxidation, so their persistence once extracted from the plant tissues is about 4 days and hence experiments longer than this duration do not reflect the bioactivity of the compound (Sampietro et al., 2009; Li et al., 2012). Our results are consistent with the inhibitory effect of Phragmites and Schoenoplectus on different species reported in literature (D'Abrosca et al., 2006; Addisie and Medellin, 2012; Chang et al., 2012). Phragmites leaf extract showed greater inhibition activity than the other plant organs on Microcystis cultures. The stem and rhizome showed a stronger decrease on Scenedesmus. For Schoenoplectus, the stem extract showed a greater inhibitory effect than the rhizome for both phytoplankton species tested.

The differences in allelopathic effects produced by aqueous extracts are partly due to the site where the bioactive substances are produced in the macrophytes. Phragmites has well developed leaf blades, where the synthesis of most of the 

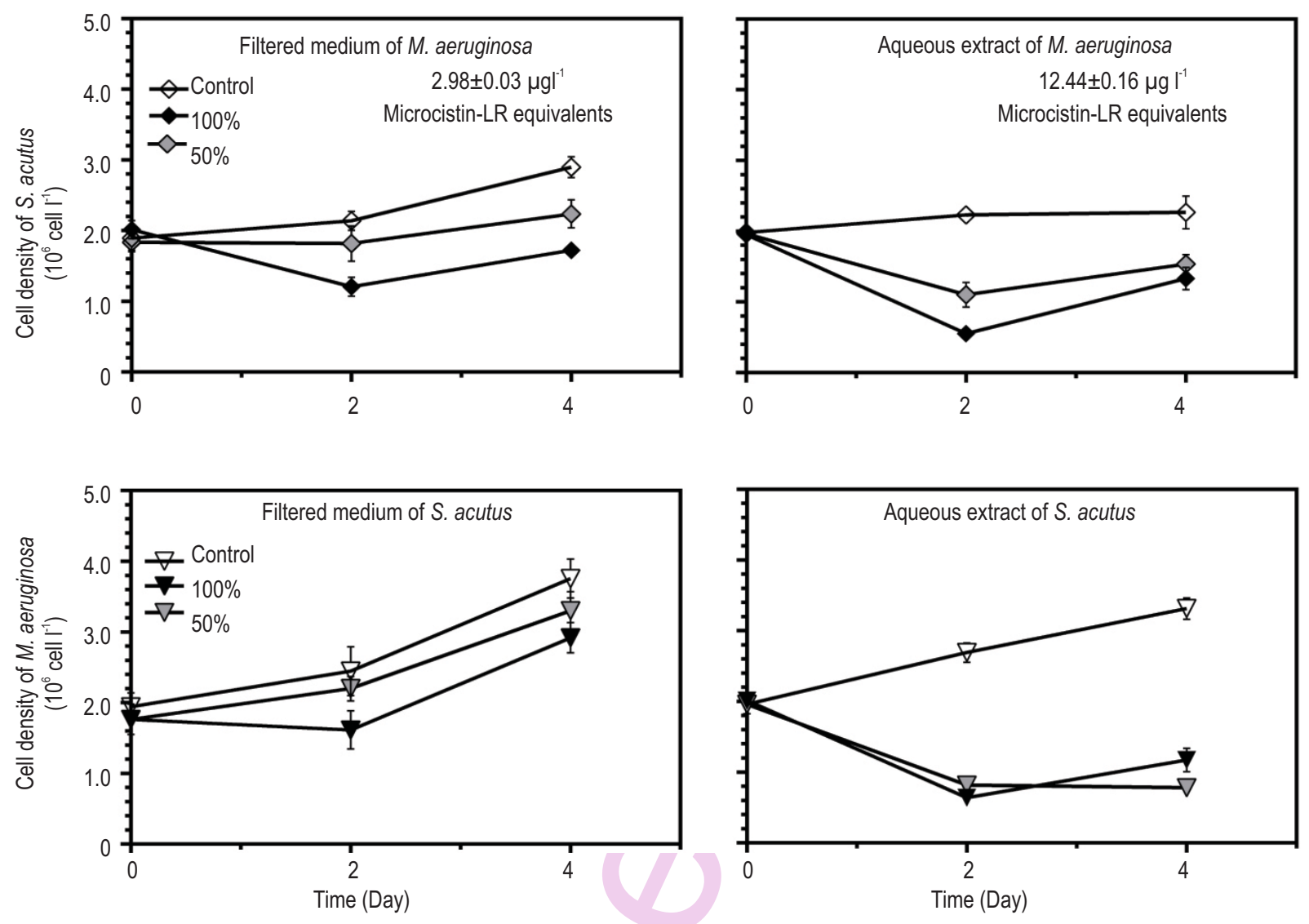

Fig. 3 : Allelopathic effect of the filtered medium and cell extract M. aeruginosa in a proportion of 100 and $50 \%$ to the cultures of $S$. acutus and vice versa. Are shown in each treatment the microstin-LR equivalents $\left(\mathrm{g} \mathrm{g}^{-1}\right)$ quantified in Microcystis cultures. Error bars are based in three replicates

secondary metabolites occurs. Schoenoplectus, on the other hand, lacks leaf blades, so the site of greatest production of secondary metabolites is the stem (Weston et al., 2012).

In this work we observed that the leaf, stem and rhizome extracts of Phragmites and Schoenoplectus showed different affinities for allelopathic activity on Microcystis and Scenedesmus, suggesting a species-specific relationship. Variability in sensitivity to bioactive substances has been reported even within species of the same genus. For example Chlorella pyrenoidosa is susceptible to Phragmites compounds but Chlorella vulgaris is not ( $\mathrm{Li}$ and $\mathrm{Hu}, 2005)$. The degree of interaction that a bioactive substance has is related to the particular characteristics of recipient species (Nakai et al., 2008; Gao et al., 2011; Sheng-hua et al., 2015). In addition, some recipient species may also develop resistance, while others do not. For example, only some recipient species in a given ecosystem exhibit a weak or no sensitivity to allelochemicals (Švanys et al., 2014).

Allelopathic activity in this work is also based on macrophyte exudates which are the allelochemicals released directly into the medium. Under conditions of water depletion the macrophytes activate various signaling mechanisms for the synthesis of new bioactive substances or retain the compounds already produced in a particular tissue (Choi et al. 2009). This condition may occur in this work and therefore the same kind of allelochemicals were consistently present in our test jars. Further we recorded that the inhibition activity of extracts from Phragmites and Schoenoplectus was most noticeable at four days of bioassay. This can be explained by exposure of the bioactive substances to other chemical forms dissolved in water, which hinder the inhibiting effect on sensitive recipient species. The dilution affects the intensity of allelopathic effects and the allelochemicals should have hydrophilic properties to reach the receptor cells (Macías et al., 2008; Gross et al., 2012). Therefore, the concentration at $20 \mathrm{mg}$ in the extracts of both macrophytes was able to cause negative effects on the growth of Microcystis and Scenedesmus as compared to $10 \mathrm{mg}$ concentration.

In the bioassays where the allelopathic effect of dissolved microcystin $\left(2.98 \pm 0.03 \mu \mathrm{gl}^{-1}\right)$ was evaluated on Scenedesmus cultures, no significant differences $(p>0.05)$ were observed when 
$50 \%$ of the filtered medium was used, with respect to controls. Only on the fourth day the density of Scenedesmus decreased. The allelopathic effect was constant during the experiment period when $100 \%$ of the filtered medium was used, resulting significantly different $(p<0.01)$ from control (Fig. 3). The filtered medium was still effective in inhibiting Scenedesmus despite the low levels of microcystin. These results contrast with other studies where microcystin at 1-10 $\mu \mathrm{gl}^{-1}$ did not cause a negative effect on S. quadricauda and S. obliquus; the allelopathic effect was observed at microcystin concentration of 50 to $\left.25000 \mu^{-1}\right|^{-1}$ (Babica et al., 2007; El Sheekh et al., 2010).

The allelopathic effect in our study could was compounded by the presence of other substances in the filtered medium of Microcystis (Bittencourt-Oliveira et al., 2013). The cell extract of $100 \%$ Microcystis $\left.\left(12.44 \pm 0.16 \mu^{-1}\right)^{-1}\right)$ had a stronger inhibitory effect than the proportion of $50 \%$ on the growth of Scenedesmus at day 2 of the assay. However, for day 4 , the $100 \%$ extract reduced its effect until reaching the proportion of $50 \%$ (Fig. 3), suggesting that the decrease on Scenedesmus was due to a chronic effect by the accumulation of microcystins. BittencourtOliveira et al. (2015) mentioned that $S$. acuminatus cultures did not suffer from allelopathic effects when exposed to crude extracts of $M$. aeruginosa at 5-10 $\mu \mathrm{g} \mathrm{I}^{-1}$ of microcystin-LR. The allelochemicals released by Scenedesmus negatively affect cyanobacteria (Jia et al., 2008; Chen and Guo, 2014), as also observed here. The inhibitory effect was more pronounced when using the cell extract. This implies that the susceptibility of cyanobacteria to the bioactive substances of Scenedesmus is high, since the low proportion was sufficient enough to cause an adverse effect similar to the $100 \%$ of the extract. These results indicate the interactions between algae and Microcystis in nature are probably more diverse than those derived from laboratory tests.

\section{Acknowledgments}

This work is a part of the academic compliance with the Graduate Program in Biological Sciences at the National Autonomous University of Mexico (UNAM). The document was made with the financial support of the National Program of Scholarships for Graduate Studies of National Council of Science and Technology (CONACYT).

\section{References}

Addisie, Y. and C. Medellin: Allelopathy in aquatic macrophytes: Effects on growth and physiology of phytoplanktons. Afr. J. Plant Sci., 6, 270-276 (2012).

Babica, P., L. Bláha and B. Maršálek: Exploring the natural role of microcystins. A review of effects on photoautotrophic organisms". J. Phycol., 42, 9-20 (2006).

Bhadoria, P.B.S.: Allelopathy: A natural way towards weed management. Am. J. Exp. Agric., 1, 7-20 (2011).

Bittencourt-Oliveira, Md., D. Camargo-Santos, A. dN.Moura, I.B.
Francisco, C.T. Dias, R.J. Molica and M.K. Cordeiro-Araújo: Effects of toxic and non-toxic crude extracts on different Microcystis species (Cyanobacteria). Afr. J. Microbiol. Res., 7, 2596-2600 (2013).

Bittencourt-Oliveira, Md., M. Chia, H. de Oliveira, M. CordeiroAraújo, R. Molica and C. Dias: Allelopathic interactions between microcystinproducing and non-microcystin-producing cyanobacteria and green microalgae: implications for microcystins production. $\mathrm{J}$. Appl. Phycol., 27, 275-284 (2015).

Chang, X., F. Eigemann and S. Hilt: Do macrophytes support harmful cyanobacteria? Interactions with a green alga reverse the inhibiting effects of macrophyte allelochemicals on Microcystis aeruginosa. Harmful Algae, 19, $76-84$ (2012).

Chen, J.Q. and R.X. Guo: Inhibition effect of green alga on cyanobacteria by the interspecies interactions. Int. J. Environ. Sci. Technol., 11, 839-842 (2014).

Choi, S.E., J.H. Yoon, H.K. Choi and M.W. Lee: Phenolic compounds from the root of Phragmites communis. Chem. Nat. Compd., 45, 893-895 (2009).

D'Abrosca, B., M. Dellagreca, A. Fiorentino, M. Isidori, P. Monaco and S. Pacifico: Chemical constituents of the aquatic plant Schoenoplectus lacustris: Evaluation of phytotoxic effects on the green alga Selenastrum capricornutum. J. Chem. Ecol., 32, 81-96 (2006).

Dittmann, E., D.F. Fewer and B.A. Neilan: Cyanobacterial toxins: Biosynthetic routes and evolutionary roots. FEMS Microbiol Rev., 37, 23-43 (2013).

El-Sheekh, M.M., H.M. Khairy and R.A. El-Shenody: Allelopathic effects of cyanobacterium Microcystis aeruginosa Kützing on the growth and photosynthetic pigments of some algal species. Allelopathy J., 26 (2010).

Erhard, D.: Allelopathy in aquatic environments. In: Allelopathy: A physiological process with ecological implications (Eds.: M.J. Reigosa, N. Pedrol and L. González). Springer, The Netherlands, pp. 433-450 (2006).

Gao, Y.N., B.Y. Liu, D. Xu, Q.H. Zhou, C.Y. Hu, F.J. Ge, L.P. Zhang and Z.B. Wu: Phenolic compounds exuded from two submerged freshwater macrophytes and their allelopathic effects on Microcystis aeruginosa. Pol. J. Environ. Stud., 20, 1153-1159 (2011).

Gross, E.M., C. Legrand, K. Rengefors and U. Tillmann: Allelochemical interactions among aquatic primary producers. In: Chemical ecology in aquatic systems (Eds.: C. Brönmark and L.A. Hansson). University Press, Oxford, pp. 196-209 (2012).

Gross, E., S. Hilt, P. Lombardo and G. Mulderii: Searching for allelopathic effects of submerged macrophytes on phytoplankton-state of the art and open questions. In: Shallow lakes in a changing world (Eds.: R. Gulati, E. Lammens, N. de Pauw and E. van Donk). Springer, Netherlands, pp. 77-88 (2007).

Hong-Qiang, W., L. Feng, Q. Ning, D. Jin-Xia, Z. Lie-Yu and G. Yi-Fei: Chemical composition of volatile oil from two emergent plants and their algae inhibition activity. Pol. J. Environ. Stud., 23, 2371-2374 (2014).

Ishida, K. and M. Murakami: Kasumigamide, an antialgal peptide from the cyanobacterium Microcystis aeruginosa. J. Org. Chem., 65, 5898-5900 (2000).

Jia, X.H., D.J. Shi, R.J. Kang, H.M. Li, Y. Liu, Z.Z. An, S.S. Wang, D.H. Song and G.S. Du: Allelopathic Inhibition by Scenedesmus obliquus of photosynthesis and growth of Microcystis aeruginosa. 
In: Photosynthesis: energy from the Sun (Eds.: J. Allen, E. Gantt, J. Golbeck and B. Osmond). Springer, the Netherlands, pp. 13391342 (2008).

Kearns, K.D. and M.D. Hunter: Toxin-producing Anabaena flos-aquae induces settling of Chlamydomonas reinhardtii, a competing motile alga. Microbial Ecology, 42, 80-86. (2001).

Leflaive, J.P. and L. Ten-Hage: Allelopathic interactions in benthic biofilms: effects of abiotic conditions on production of and sensitivity to allelo chemicals. J. N. Am. Benthol. Soc., 28, 273-282 (2009).

Li, F.M. and Y.H. Hu: Isolation and characterization of a novel antialgal allelochemical from Phragmites communis. Appl. Environ. Microbiol., 71, 6545-6553 (2005).

Li, X., B.S. Cui, Q.C. Yang, Y. Lan, T.T. Wang and Z. Han: Litter quality and interactions of macrophytes tissues decomposition in a eutrophic shallow lake. Procedia Environ. Sci., 13, 1170-1178 (2012).

Lin, Q., S.S.S. Sarma and B.P. Han: Effect of cyanobacterium on competition between rotifers: a population growth study. Inland Waters, 4, 319-216 (2014).

Macías, F., J.L. Galindo, M. García-Díaz and J.G. Galindo: Allelopathic agents from aquatic ecosystems: potential biopesticides models. Phytochem Rev., 7, 155-178 (2008).

Nakai, S., G. Zou, X. Song, Q. Pan, S. Zhou and M. Hosomi: Release of anti-cyanobacterial allelochemicals from aquatic and terrestrial plants applicable for artificial floating islands. J. Water Environ. Technol., 6, 55-63 (2008).

Neilan, B.A., L. A. Pearson, J. Muenchhoff, M.C. Moffitt and E. Dittmann: Environmental conditions that influence toxin biosynthesis in cyanobacteria. Environ. Microbiol., 15, 1239-1253 (2013).

NIVA: Estimation of algal growth potential. Norwegian Inst. for Water Res, Publ. D2-25 (1976).

Rao, B.D., M. R. Babu and N. Ellaswamy: Cyanotoxins and their potential applications. Areview. Nat. Envr. Pollu. Technol., 14, 203-9 (2015).

Rudrappa, T., J. Bonsall, J. Gallagher, D. Seliskar and H. Bais: Rootsecreted allelochemical in the noxious weed Phragmites australis deploys a reactive oxygen species response and microtubule assembly disruption to execute rhizotoxicity. J. Chem. Ecol., 33, 1898-1918 (2007).

Sampietro, D.A., C.A. Catalan and M.A. Vattuone: Isolation, identification and characterization of allelochemicals/natural products. Science Publishers. (2009).

Sheng-hua, Z., G. Li, C. Jin-yan and C. Jun-jun: Allelopathic activities of three emergent macrophytes on several monospecific cyanobacterial species and natural phytoplankton assemblages. Pol. J. Environ. Stud., 24, 397-402 (2015).

Staub, R.: Ernarungsphysiologische Untersuchungenan der planktischen Blaualge Oscillatoria rubescens D.C. Schweiz Z Hydrol, 23, 82-198 (1961).

Švanys, A., R. Paškauskas and S. Hilt: Effects of the allelopathically active macrophyte Myriophyllum spicatum on a natural phytoplankton community: A mesocosm study. Hydrobiology, 737, 57-66 (2014).

Thorpe, A.S., E.T. Aschehoug, D.Z. Atwater and R.M. Callaway: Interactions among plants and evolution. J. Ecol., 99, 729-740 (2011).

Uddin, M.N., D. Caridi and R.W. Robinson: Phytotoxic evaluation of Phragmites australis: an investigation of aqueous extracts of differentorgans. Mar. Freshw. Res., 63, 777-787 (2012).

Weston, L.A., P.R. Ryan and M. Watt: Mechanisms for cellular transport and release of allelochemicals from plant roots into the rhizosphere. J. Exp. Bot., 63, 3445-3454 (2012).

Yang, J., X. Deng, Q. Xian, X. Qian and A. Li: Allelopathic effect of Microcystis aeruginosa on Microcystis wesenbergii: microcystinLR as a potential allelochemical. Hydrobiologia, 727, 65-73 (2014). 